VOLUME 17 NOMOR 4, OKTOBER 2018

\title{
SOSIALISASI KEAMANAN SISTEM INSTALASI LISTRIK DAN HEMAT ENERGI DI BANJAR TINGKIH KEREP - PENEBEL TABANAN
}

\author{
I G N Janardana ${ }^{1}$, I W Arta Wijaya ${ }^{2}$, N Budiastra ${ }^{3}$, W Sukerayasa ${ }^{4}$ W G \\ Ariastina $^{5}$
}

\begin{abstract}
ABSTRAK
Instalasi Listrik merupakan salah untuk menyalurkan tenaga listrik dari pusat pembangkit ke pusat beban. Kebakaran gedung diakibatkan oleh listrik sering terjadi. Kebakaran tersebut diakibatkan beberapa hal seperti : instalasi yang tidak sesuai standar PUIL, penggunaan kotak kontak menumpuk, pemeliharaan instalasi kurang teratur, umur instalasi melebihi standar. Permasalahan tersebut penting diatasi dengan melakukan sosialisasi keamanan instalasi listrik bagi masyarakat untuk menghindari terjadinya bahaya kebakaran pada gedung. Pemahaman tentang hemat energi juga penting bagi masyarakat agar masyarakat dapat menghemat biaya listrik. Sasaran dari pengabdian ini adalah masyarakat yang sehari-hari mengoperasikan peralatan listrik di Banjar Tingkih Kerep, Kecamatan Penebel Kabupaten Tabanan. Berdasarkan hasil pelaksanaan pengabdian kepada masyarakat dari kegiatan persiapan hingga pelaksanaan yang dilaksanakan pada bulan Agustus sampai bulan Nopember 2017, sosialisasi bertempat di Balai Banjar Tingkih Kerep dengan metode ceramah dengan alat peraga instalasi listrik berdasarkan PUIL 2011[1]. dan sosialisasi hemat energi serta diskusi. Dilanjutkan dengan pemasangan stiker bahaya listrik dan stiker hemat energi ke rumah-rumah penduduk. Hari berikutnya dilanjutkan dengan pemasangan lampu penerangan luar dengan kabel tanam sebagai contoh instalasi listrik yang benar. Terakhir dilakukan evaluasi hasil kegiatan sosialisasi yang telah dilakukan kepada masyarakat dan masyarakat menyatakan memahami pemakaian listrik yang benar.
\end{abstract}

Kata Kunci: Instalasi listrik, Keamanan Instalasi, Hemat Energi

12,3,4,5 Program Studi Teknik Elektro, Fakultas Teknik, Universitas Udayana, Kampus Bukit Jimbaran, Indonesia. janardana@ unud.ac.id 


\section{PENDAHULUAN}

\subsection{Analisis Situasi}

Banjar Tingkih Kerep, Kecamatan Penebel Kabupaten Tabanan merupakan salah satu desa dengan. batas desa sebagai berikut: Sebelah utara Desa Adat Puakan, sebelah Timur Desa Adat Puluk-Puluk, sebelah Selatan Desa Adat Tegal Linggah dan sebelah barat Desa Tegayang. Keseluruhan masyarakat telah menikmati listrik yang dari listrik PLN kira-kira sejak tahun 1992, sehingga banyak instalasi listrik tersebut telah berumur lebih dari 20 tahun. Sehingga terjadi kerawanan terhadap bahaya kebakaran bila instalasi listrik tersebut tidak dipelihara. Saat ini masyarakat memiliki tingkat perekonomian yang meningkat, sebagian besar masyarakat memiliki banyak peralatan rumah tangga seperti kulkas, TV, Rice Cooker, Hand Phone dan lain-lain. Semua peralatan elektronik tersebut dicatu oleh listrik, namun tidak dibarengi dengan pengembangan instalasi sesuai standar PUIL 2011, melainkan dengan menumpuk stop kontak pada satu titik instalasi stop kontak. Hal tersebut banyak terjadi di masyarakat. Masalah tersebut sebagai pemicu terjadinya percikan bunga api dan juga kemampuan peralatan listrik seperti kotak kontak dan kabel melebihi kemampuan hantar arus, sehingga menyebabkan kebakaran [2], [3], [4], [5].

Maka perlu dilakukan pengabdian kepada masyarakat agar menggunakan listrik secara tepat hemat biaya listrik [6].

Berdasarkan permasalahan di atas maka tim pengabdian melaksanakan pengabdian di Banjar Tingkih Kerep dengan metode ceramah menggunakan alat peraga pengoperasian dan penggunaan peralatan listrik yang baik dan benar seperti : bahaya listrik, pengoperasian peralatan, hemat energi maupun pemeliharaan instalasi listrik.

\subsection{Perumusan Masalah}

Bagaimana penyampaian informasi tentang pengoperasian dan penggunaan listrik yang baik dan benar sehingga tidak terjadi kebakaran dan cara menghemat energi listrik.

\subsection{Tujuan Kegiatan}

1. Supaya bisa mengoperasikan peralatan listrik secara baik, tepat dan benar, sehingga tidak terjadi bahaya pada manusia dan bangunan.

2. Supaya bisa menghemat energi listrik yang dapat menghemat biaya dan dapat memeberikan kesempatan menikmati energy listrik bagi masyarakat yang belum mendapatkan listrik.

\subsection{Manfaat Kegiatan}

Bagi masyarakat diharapkan dapat mengenal instalasi listrik yang benar sesuai standar PUIL 2011, sehingga tidak terjadi bahaya baik terhadap manusia maupun bangunannya serta masyarakat mampu menghemat energi listrik. 


\section{METODE PEMECAHAN MASALAH}

Tim Pengabdian Kepada Masyarakat telah melakukan kegiatan sebagai berikut :

1. Memberikan ceramah kepada masyarakat konsep instalasi kelistrikan yang baik dan benar sesuai PUIL 2011

2. Memperagakan alat peraga instalasi listrik sehingga anggota masyarakat bisa menyaksikannya secara langsung instalasi listrik yang benar, cara penyambungan kabel, pemasangan isolasi, dan lain-lain.

3. Memberikan/memasang instalasi listrik di fasilitas umum sebagai contoh instalasi listrik yang benar kepada masyarakat.

4. Pemasangan stiker-stiker tentang hemat energi ke rumah-rumah penduduk dan fasilitas umum serta cara-cara pengoperasian peralatan rumah tangga yang dicatu oleh daya listrik agar masyarakat dapat menghemat energi listrik dan pemasangan stiker penggunaan stop kontak yang benar dan stop kontak yang salah agar terhindar dari bahaya kebakaran.

5. Mengadakan diskusi dengan masyarakat baik pada saat diadakan sosialisasi maupun pada saat pemasangan stiker.

6. Melakukan evaluasi ke desa hasil sosialisasi yang telah dilakukan.

\section{HASIL DAN PEMBAHASAN}

\subsection{Realisasi Pemecahan Masalah}

Pemecahan masalah dilakukan sebagai berikut :

1. Identifikasi instalasi listrik di masyarakat yang belum sesuai standar PUIL seperti penggunaan kabel NYF, pengoperasian stop kontak(kotak kontak) menumpuk melebihi aturan, isolasi tidak standar, cara penyambungan kabel, pengoperasian lampu berlebih dan lain-lain.

2. Memperbaiki instalasi listrik pada salah satu instalasi yang salah tentang penyambungan kabel, isolasi sebagai contoh instalasi yang benar ke masyarakat.

3. Penanaman kabel tanam sesuai aturan/standar sekaligus sebagai contoh yang dapat ditiru oleh masyarakat.

4. Pemasangan stiker-stiker tentang hemat energi, stiker penggunaan stop kontak yang salah, stiker penggunaan stop kontak yang benar pada dinding rumah ke seluruh rumahrumah penduduk serta pada tempat-tempat umum. 


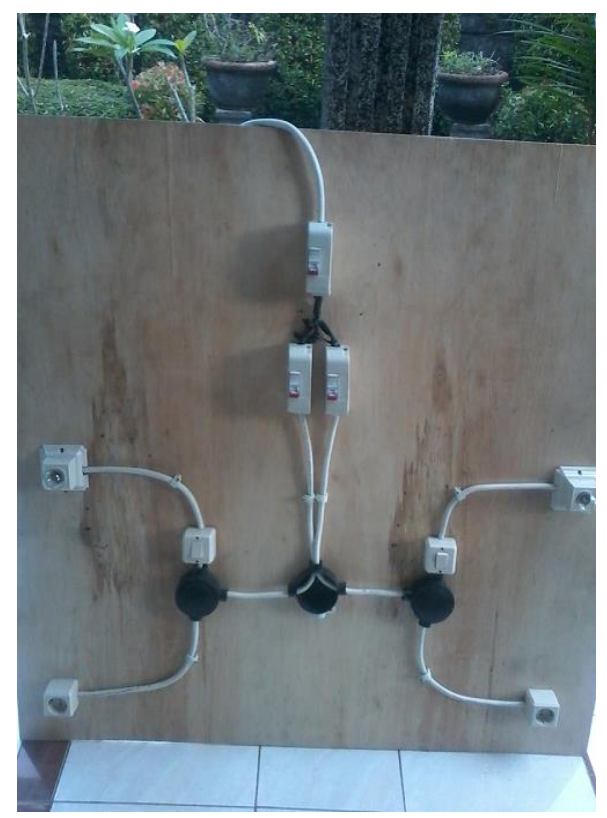

Gambar 4.1 Foto Kegiatan Sosialisasi Jenis Peralatan Listrik Standar Dengan Alat Peraga

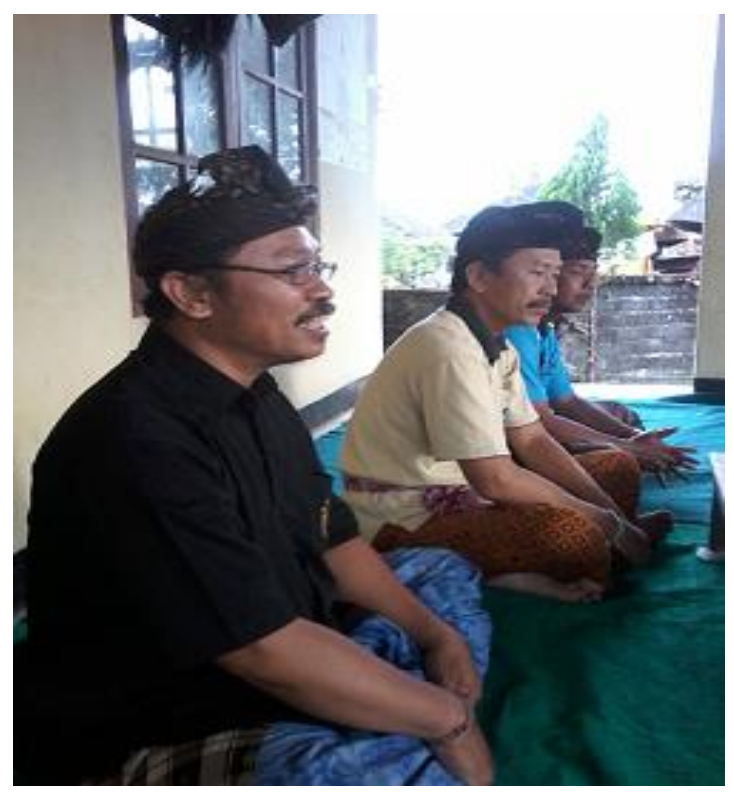

Gambar 4.2 Foto Sosialisasi Aturan Instalasi Rumah Tinggal Dan Instalasi Luar 


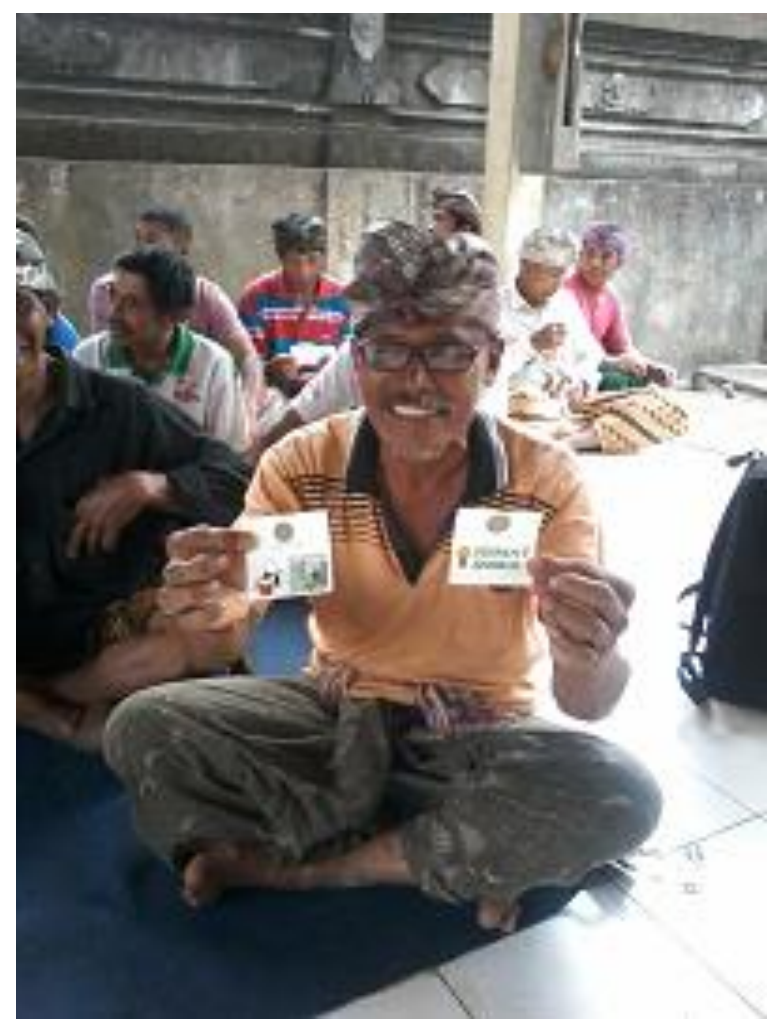

Gambar 4.3 Foto Kegiatan Sosialisasi Hemat Energi Dengan Peragaan Stiker

\subsection{Hasil Pelaksanaan Kegiatan}

1. Beberapa masyarakat mampu dan memahami memasang instalasi penerangan luar yang dipasang di Pura dan di Balai Banjar Tingkih Kerep seperti gambar 4.4.

2. Masyarakat mengetahui pemeliharaan instalasi listrik yang benar dan memahami umur instalasi yang sesuai standar.

3. Beberapa masyarakat memahami kondisi instalasi listrik rumahnya yang telah lewat dari standar yang diijinkan oleh PUIL 2011, sehingga masyarakat sudah menyiapkan diri untuk merenovasi instalasi listriknya untuk menghindari bahaya kebakaran akibat instalasi listrik yang sudah rusak.

4. Masyarakat mampu melakukan penghematan energi dengan mengoperasikan beberapa peralatan elektronik rumah tangga seperti Magic Jar, kulkas dan lain-lain sesuai kebutuhan dan waktu yang tepat.

5. Masyarakat diberikan batasan-batasan dan jenis-jenis kabel yang boleh dipergunakan. 


\section{Kesimpulan}

1. Masyarakat sudah mendapatkan sosialisasi dalam bentuk ceramah dan menyaksikan demontrasi dengan alat peraga instalasi listrik yang benar dan jenis-jenis kabel yang sesuai standar.

2. Masyarakat ikut serta menyaksikan pemasangan instalasi luar yang dipasang di Pura dan Balai Bamjar.

3. Masyarakat mampu mengoperasikan peralatan elektronik rumah tangga dengan efisien sehingga dapat menghemat energi.

4. Masyarakat bersama-sama memasang stiker-stiker hemat energi dan penggunaan stop kontak yang benar di rumah-rumah penduduk dan fasilitas umum sebagai upaya mengajak masyarakat untuk hemat energi dan menggunakan instalasi listrik sesuai standar.

\section{DAFTAR PUSTAKA}

[1] ------, 2011. Persyaratan Umum Instalasi Listrik ( PUIL 2011). Jakarta

[2] Budiman, M. Dkk. 2000. Panduan Instalasi Listrik Untuk Rumah Berdasarkan PUIL 2000. Jakarta : Yayasan Usaha Penunjang Tenaga Listrik Bekerja sama dengan Copper Development Centre. South East Asia.

[3] Handoko, P. 2000. Pemasangan Instalasi Listrik Dasar. Yogyakarta : Kanisius.

[4] Harten, PV. Terjemahan : Setiawan E. 1991. Instalasi Listrik Arus Kuat 1. Bandung : Bina Cipta.

[5] Harten, PV. Terjemahan : Setiawan E. 1991. Instalasi Listrik Arus Kuat 2. Bandung : Bina Cipta.

[6] Harten, PV. Terjemahan : Setiawan E. 1991. Instalasi Listrik Arus Kuat 3. Bandung : Bina Cipta. 